\title{
Daily intake of Kaempferia parviflora extract decreases abdominal fat in overweight and preobese subjects: a randomized, double-blind, placebo-controlled clinical study
}

This article was published in the following Dove Press journal: Diabetes, Metabolic Syndrome and Obesity:Targets and Therapy

\author{
Susumu Yoshino' \\ Riyo Awa' \\ Yasuo Miyake' \\ Ikuo Fukuhara \\ Hisao Sato ${ }^{3}$ \\ Toyotada Ashino 3 \\ Shinpei Tomita ${ }^{3}$ \\ Hiroshige Kuwahara' \\ 'Research and Development \\ Division, Research Center, Maruzen \\ Pharmaceuticals Co., Ltd., Hiroshima, \\ Japan; ${ }^{2}$ Fukuhara Clinic, Hokkaido, \\ Japan; ${ }^{3}$ Clinical Research Department, \\ New Drug Research Center, Inc., \\ Hokkaido, Japan
}

Purpose: Obesity is a serious problem, which is now a worldwide health problem. Kaempferia parviflora extract (KPE) exhibits anti-obesity effects in animals. However, as no clinical trials have evaluated the anti-obesity effects of KPE in humans, we examined the effects of KPE in reducing abdominal fat in overweight and preobese Japanese subjects.

Materials and methods: A 12-week, single-center, randomized, double-blind, placebocontrolled clinical trial was conducted. Seventy-six subjects (males and females aged 20 to $<65$ years) with a body mass index $\geq 24$ and $<30 \mathrm{~kg} / \mathrm{m}^{2}$ were randomly assigned into two groups. The subjects in each group ingested one capsule of placebo or active KPE (containing $150 \mathrm{mg}$ of KPE) once daily for 12 weeks. The primary outcome was reduction in visceral fat area as determined by computed tomography scanning. The key secondary outcomes were reductions in subcutaneous fat area and total fat area. Subgroup analysis was also performed in healthy subjects without dyslipidemia, hypertension, or hyperglycemia. The safety of KPE ingestion was also evaluated.

Results: Compared with the placebo group, the active KPE group exhibited significant reduction in abdominal fat area (visceral, subcutaneous, and total fat) and triglyceride levels after 12 weeks. Subgroup analyses demonstrated a significant reduction in abdominal fat area and triglyceride levels in healthy subjects compared with the placebo group after 12 weeks. Neither group exhibited adverse events related to the test foods or clinically relevant abnormal changes in physical, biochemical, or hematologic parameters, or in urinalysis results and medical interview. Conclusion: Daily ingestion of KPE safely reduces body fat, particularly abdominal fat, in Japanese overweight and preobese subjects.

Keywords: healthy subjects, metabolic disorder, obesity, randomized clinical trial, triglyceride, visceral fat

\section{Introduction}

Obesity is a serious global health problem. In Japan, $>30 \%$ of adult men and $20 \%$ of adult women are categorized as preobese or obese, based on a body mass index (BMI) of $\geq 25 \mathrm{~kg} / \mathrm{m}^{2}$. Obesity is a significant risk factor for development of metabolic disorders such as insulin resistance, hyperlipidemia, and hypertension, which in turn are risk factors for cardiovascular diseases. ${ }^{1-3}$ Obesity develops when there is an imbalance between energy intake and expenditure and is characterized by increased body weight resulting from excessive lipid accumulation. ${ }^{4}$ Accumulation of excessive fat in adipocytes increases the risk of developing type 2 diabetes associated with insulin resistance. ${ }^{5,6}$ Strategies to prevent and improve obesity, particularly by decreasing
Correspondence: Susumu Yoshino Research and Development Division, Research Center, Maruzen Pharmaceuticals Co, Ltd., I089-8 Sagata, Shin-ichi, Fukuyama, Hiroshima 7293102 , Japan

Tel +81847525501

Fax +8I 847525900

Email s-yoshino@maruzenpcy.co.jp 
visceral fat accumulation, are thus important in the control of these metabolic diseases. Various so-called functional foods or natural components for preventing or improving obesity have been developed recently. Several of these foods reportedly inhibit the development of obesity, and some have been used to achieve body fat loss. ${ }^{7-10}$

Kaempferia parviflora Wall. ex Baker (KP), also known as Krachai-Dam or black ginger in Thailand, is a plant belonging to the family Zingiberaceae. KP rhizomes are used in folk medicine to improve blood flow and treat inflammatory, allergic, and gastrointestinal disorders. KP also reportedly exhibits beneficial activities, such as anticholinesterase, ${ }^{11}$ antiinflammatory, ${ }^{12-14}$ spasmolytic, ${ }^{15}$ gastric ulcer amelioration, ${ }^{16}$ antioxidative, ${ }^{17}$ and vasodilatory ${ }^{18}$ effects in addition to regulation of adipocyte differentiation. ${ }^{19,20}$ Dietary supplementation with KP extract (KPE) also reportedly suppresses body weight increases, body fat accumulation, and glucose intolerance in obese mice. ${ }^{21-23}$ Other reports suggest that oral intake of KPE increases energy expenditure and fat utilization. ${ }^{23-25}$ Collectively, these findings suggest that KPE could be used to reduce body fat in humans; however, there are no human clinical data to support this hypothesis.

The World Health Organization defines obesity as a BMI $\geq 30 \mathrm{~kg} / \mathrm{m}^{2}$ and preobesity as a BMI $\geq 25$ but $<30 \mathrm{~kg} / \mathrm{m}^{2}{ }^{26}$ The Japan Society for the Study of Obesity has classified persons with a BMI between 23 and $25 \mathrm{~kg} / \mathrm{m}^{2}$ as "overweight" and those with a BMI between 25 and $30 \mathrm{~kg} / \mathrm{m}^{2}$ as "obese level 1 (preobese)". The overall goal of the present study was to investigate whether dietary KPE ingestion reduces abdominal fat in Japanese overweight and preobese subjects. We hypothesized that dietary KPE ingestion would reduce visceral fat in healthy subjects with no metabolic abnormalities due to increased lipolysis and energy expenditure. We, therefore, also performed subgroup analyses of healthy subjects without elevated triglycerides (TGs), reduced highdensity-lipoprotein cholesterol (HDL-Cho), elevated blood pressure, and elevated fasting blood glucose (FBG). In addition, we evaluated the safety of KPE ingestion by monitoring adverse events.

\section{Materials and methods Study design}

A randomized, double-blind, placebo-controlled study designed to evaluate the efficacy and safety of KPE ingestion was carried out in accordance with the Declaration of Helsinki and the Japanese Ethical Guidelines for Medical and Health Research Involving Human Subjects. The study protocol and all related documents were approved by the Miyawaki
Orthopedics Clinic Institutional Review Board (Hokkaido, Japan; date of approval: February 20, 2017; approval No: 16211) - an agency not involved in this study - to ensure that approval for the study was unbiased and that there were no conflicts of interest. Appropriate explanations were provided to subjects regarding the study's purpose, content, procedures, methods, and potential adverse reactions. All subjects gave their signed written informed consent before participating in the study. The study was conducted at the Fukuhara Clinic (Hokkaido, Japan) between April 2017 and July 2017 under control of the principal investigator. The data were analyzed from September to December, 2017. The study is registered under clinical trial registration number UMIN000026291. A data monitoring manager assured accuracy of data collection and inputs.

\section{Subjects}

Subjects were Japanese adults (men and women) aged 20 to $<65$ years with a BMI $\geq 24 \mathrm{~kg} / \mathrm{m}^{2}$ and $<30 \mathrm{~kg} / \mathrm{m}^{2}$. In total, 214 subjects (men: $n=103$, women: $n=111$ ) agreed to participate and were enrolled by the New Drug Research Center, Inc. (Tokyo, Japan). The exclusion criteria were as follows: history of severe illness affecting the heart, liver, kidney, or digestive organs; meeting the diagnostic criteria for metabolic syndrome (visceral fat area $[\mathrm{VFA}] \geq 100 \mathrm{~cm}^{2}$ plus fewer than two of the following: elevated TGs and/or reduced HDL-Cho, elevated blood pressure, and elevated $\mathrm{FBG})^{27}$; underwent medical treatment or surgery within 2 months before this study; use of drugs affecting carbohydrate metabolism and lipid metabolism; use of antihypertensive drugs; continual use of oral medications and foods affecting body fat or lipid metabolism; possible pregnancy, pregnancy, and lactation; heavy alcohol consumption; difficulty in collecting blood; donated $\geq 200 \mathrm{~mL}$ of blood within 1 month before this study; constipated for $>5$ days; shift worker; allergic to the test foods; participation in another clinical study; any other reason for ineligibility as judged by the principal investigator. Based on these criteria, 138 subjects were excluded from the study. Figure 1 shows a flowchart for the study.

\section{Test food}

Two types of capsules were prepared: "active" capsules containing KPE powder TM (Maruzen Pharmaceuticals, Hiroshima, Japan) and placebo capsules without KPE. Active and placebo capsules were indistinguishable in terms of flavor and appearance, including color, size, and packaging. The composition and nutritional content of both types of capsule are shown in Table 1. Standardization and conformity of the 


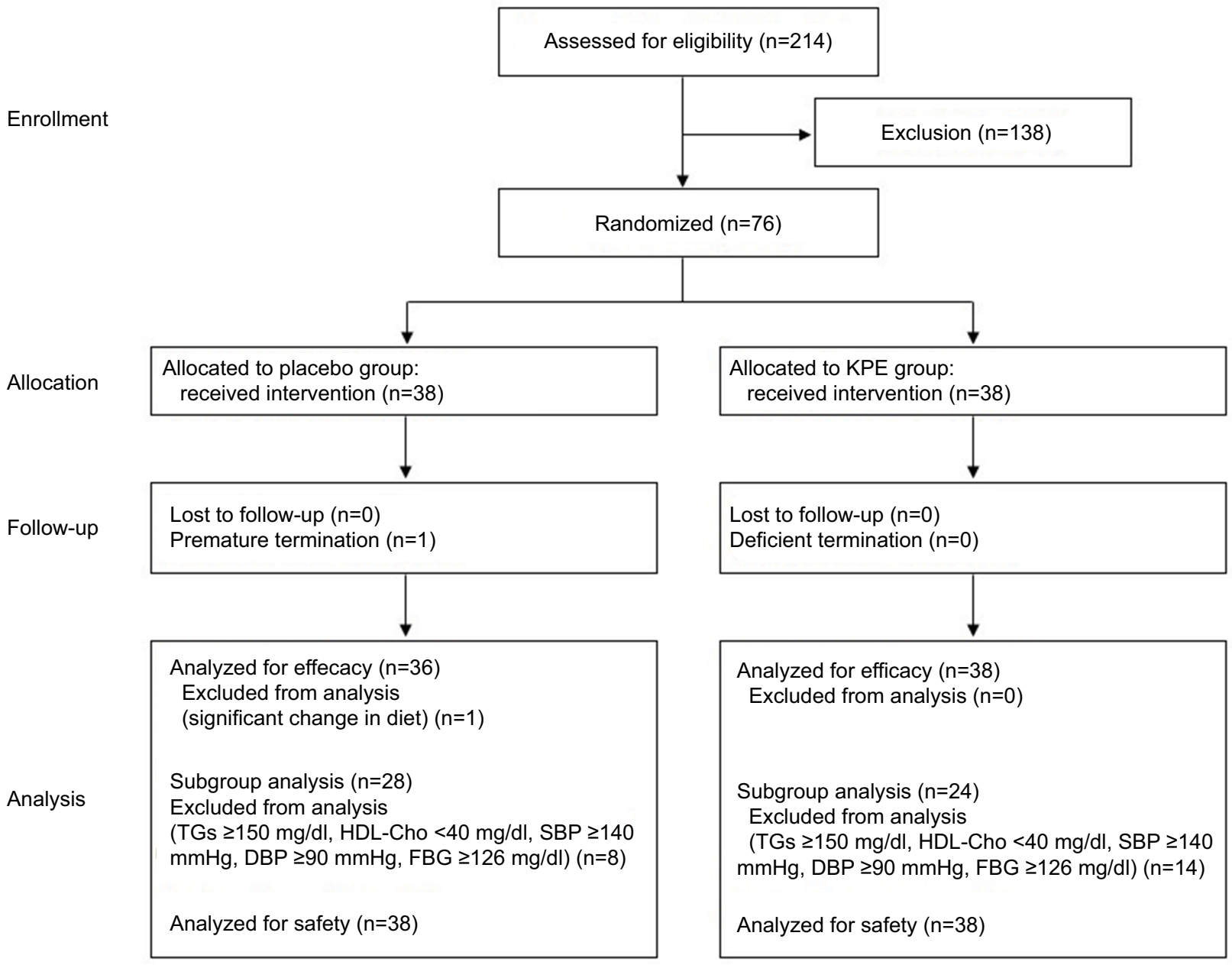

Figure I Flowchart illustrating the phases of the study.

Abbreviations: Cho, cholesterol; DBP, diastolic blood pressure; FBG, fasting blood glucose; HDL, high-density lipoprotein; KPE, Kaempferia parviflora extract; SBP, systolic blood pressure; TGs, triglycerides.

Table I Composition and nutritional content of test foods

\begin{tabular}{lll}
\hline Food characteristics & \multicolumn{2}{l}{ Serving size: I capsule (308 mg) } \\
\cline { 2 - 3 } & Placebo & KPE \\
\hline Composition & 0.0 & 150.0 \\
KPE (mg) & 242.5 & 92.5 \\
Dextrin (mg) & 2.5 & 2.5 \\
Calcium stearate (mg) & 63.0 & 63.0 \\
Gelatin cap (mg) & 1.16 & \\
Nutritional content per capsule & 1.18 \\
Energy (kcal) & 0.06 & 0.07 \\
Protein (g) & 0.23 & 0.21 \\
Carbohydrate (g) & 0.00 & 0.01 \\
Fat (g) &
\end{tabular}

Abbreviation: KPE, Kaempferia parviflora extract.

KPE used in the active capsules were assured by implementation of strict in-process controls during manufacture and complete analytical control of the resulting dry extract. The KPE used in the active capsules included standardized polymethoxyflavone $(>8 \%)$, a total of six compounds analyzed by high-performance liquid chromatography: 5,7-dimethoxyflavone; 3,5,7-trimethoxyflavone; 5,7,4'-trimethoxyflavone;

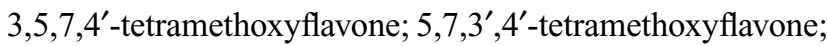
and $3,5,7,3^{\prime}, 4^{\prime}$-pentamethoxyflavone.

\section{Randomization and blinding}

Randomization was performed by Statcom Company Limited (Tokyo, Japan) using a computer-generated permuted block randomization scheme. After stratifying by age, gender, and VFA, eligible participants were randomized to active KPE group or placebo group, with an allocation ratio of $1: 1$. Allocation manager who had no contact with the subjects, outcome evaluator, and data collector generated a random number sequence list. The random sequence was kept by a designated person who was in charge of assignment of the test foods to subjects. Allocation manager and the designated person who was in charge of assignment were not involved in the study design, subject recruitment, assessment, data 
collection, intervention, or analysis. All subjects and investigators were blinded to the group assignment. The randomization code was opened after the dataset was carefully checked, cleaned, and fixed.

\section{Study schedule}

Each subject received one capsule per day for 12 weeks, and they visited the clinic for assessments and measurements on Weeks 0 (0W, at the start of intake), 4 (4W), $8(8 \mathrm{~W})$, and 12 $(12 \mathrm{~W})$. The subjects were instructed to drink only water after 9:00 pm on the day before the visit until the examination was completed on the following day. On the day of examination, smoking was prohibited until the examination was completed. During the study period, subjects were instructed not to use oral medications, dietary supplements, or functional foods affecting body fat or lipid metabolism, and we instructed the subjects not to significantly change their daily routines or lifestyle compared with before initiation of the study. Physical parameters (height, body weight, BMI, waist circumference, body temperature, blood pressure, and heart rate), hematologic parameters, blood biochemical parameters, urinalysis, and abdominal fat area were assessed for all subjects.

\section{Target sample size}

Based on another preliminary human study, capsules containing $150 \mathrm{mg}$ of KPE were predicted to reduce body fat by $2.5 \%$ (SD $4.4 \%$ ) compared with the placebo capsules $(-0.5 \%$ [SD $4.4 \%]$ ). To detect a difference with a power of $80 \%$ at a significance level of $\alpha=0.05$, the number of subjects required per group was estimated as 35 . To account for an expected dropout rate of $10 \%$, the number of subjects required per group was estimated as 38 .

\section{Measurement of abdominal fat area}

Subjects underwent computed tomography (CT) scanning of the abdominal transverse section at the umbilical position using a Robusto-Ei scanner (Hitachi Medico, Tokyo, Japan). Abdominal body fat area (VFA and subcutaneous fat area [SFA]) values were calculated based on analysis of the abdominal CT scan using visceral fat measurement software (Fat Scan ${ }^{\mathrm{TM}}$ Ver. 3.0, N2 Systems Inc., Osaka, Japan). The abdominal total fat area (TFA) was calculated as the sum of the VFA and SFA. In consideration of the risk of radiation exposure, subjects underwent $\mathrm{CT}$ scans only at the initial screening and at $0 \mathrm{~W}, 8 \mathrm{~W}$, and $12 \mathrm{~W}$. The primary outcome was reduction in VFA at $8 \mathrm{~W}$ and $12 \mathrm{~W}$. The key secondary outcomes were reductions in TFA and SFA at $8 \mathrm{~W}$ and $12 \mathrm{~W}$.

\section{Physical and blood examinations and urinalysis}

Height was measured only at the screening examination. Body weight, BMI, waist and hip circumference, body temperature, systolic blood pressure (SBP), diastolic blood pressure (DBP), and heart rate were measured at each examination. BMI was calculated as body weight (in $\mathrm{kg}$ )/height (in $\mathrm{m}^{2}$ ). Blood pressure and heart rate were measured after rest for about 5 minutes with the subject in the sitting position.

The following fasting blood sample parameters were measured: white blood cell (WBC) count, red blood cell (RBC) count, hemoglobin, hematocrit, platelets, mean corpuscular volume, mean corpuscular hemoglobin, and mean corpuscular hemoglobin concentration for hematology; and total protein, albumin, total bilirubin (T-bil), aspartate aminotransferase, alanine aminotransferase, lactate dehydrogenase, alkaline phosphatase, $\gamma$-glutamyltranspeptidase, creatine phosphokinase, total cholesterol, HDL-Cho, lowdensity-lipoprotein cholesterol (LDL-Cho), TGs, FBG, hemoglobin A1c (HbA1c), uric acid, blood urea nitrogen $(\mathrm{BUN})$, creatinine, sodium $(\mathrm{Na})$, chloride $(\mathrm{Cl})$, potassium $(\mathrm{K})$, calcium $(\mathrm{Ca})$, magnesium $(\mathrm{Mg})$, and iron $(\mathrm{Fe})$ for biochemical analyses. All blood analyses were performed by a commercial clinical laboratory (SRL Inc., Tokyo, Japan).

The semiquantitative analyses of urine protein, urine glucose, urobilinogen, bilirubin, ketone bodies, and urine occult blood were performed using fasting urine samples. Urine $\mathrm{pH}$ was also measured. All urinalyses were performed by a commercial clinical laboratory (SRL Inc.).

\section{Dietary record and physical activity}

Subjects recorded the content of their daily meals, snacks, and beverages (except for water), as well as the number of steps counted using a pedometer. Values of dietary and physical activity were recorded on a paper for 3 days prior to each visit at $0 \mathrm{~W}, 4 \mathrm{~W}, 8 \mathrm{~W}$, and $12 \mathrm{~W}$. Based on the meal survey, a nutritionist calculated each subject's energy intake. The daily average number of steps counted was calculated as physical activity. Subjects also recorded the time of test food ingestion, subjective symptoms, and daily activities, including eating habits, exercise habits, alcohol intake, and drug intake. The rate of test food intake was calculated based on subject's daily paper record.

\section{Subgroup analyses}

To evaluate the effects of KPE in healthy subjects with no metabolic abnormalities, we performed subgroup analyses. The following diagnostic criteria are used to diagnose 
metabolic syndrome in Japan: elevated TGs $(\geq 150 \mathrm{mg}$ / $\mathrm{dL})$, reduced HDL-Cho $(<40 \mathrm{mg} / \mathrm{dL})$, elevated SBP $(\geq 140$ $\mathrm{mmHg})$, elevated DBP $(\geq 90 \mathrm{mmHg})$, and elevated FBG $(\geq 126$ $\mathrm{mg} / \mathrm{dL}$ ). In the subgroup analyses, we evaluated the effect of KPE in healthy subjects with BMI $\geq 24$ and $<30 \mathrm{~kg} / \mathrm{m}^{2}$, TGs $<150 \mathrm{mg} / \mathrm{dL}$, HDL-Cho $\geq 40 \mathrm{mg} / \mathrm{dL}, \mathrm{SBP}<140 \mathrm{mmHg}$, DBP $<90 \mathrm{mmHg}$, and $\mathrm{FBG} \leq 125 \mathrm{mg} / \mathrm{dL}$.

\section{Statistical analysis}

Data are expressed as mean values with SD. All randomized (intention-to-treat [ITT]), per-protocol analyses (PPS) and subgroup analyses were performed. The data are reported ITT for the background of subjects and safety evaluation and PPS for the efficacy evaluation.

An $F$-test was used to assess homoscedasticity between the placebo and active food groups. If homoscedasticity was confirmed, the Student's $t$-test was used, whereas AspinWelch's $t$-test was used for comparisons if the variances were unequal. In addition, Wilcoxon's rank sum test was used for comparisons between the placebo and active food groups in urine semiquantitative analyses. For primary and secondary endpoints, the effect of two factors (time and group) and timeby-group interactions were analyzed by repeated measures analysis of variance (ANOVA) using values obtained during the test food ingestion period. The level of statistical significance was set at $p<0.05$. Statistical analyses were performed using Microsoft Excel ${ }^{\circledR} 2013$ (Microsoft Corp., Redmond, WA, USA) and SAS ${ }^{\circledR} 9.3$ (SAS Institute Inc., Cary, NC, USA).

\section{Results}

After exclusion of 138 subjects in the screening examination based on the abovementioned exclusion criteria, 76 subjects ( $m e n=16$, women=60) were randomized into the KPE and placebo groups (38 subjects per group). One subject subsequently dropped out of the study because of personal issues not related to the study. Of the 75 subjects who completed the study, 1 was excluded from the efficacy evaluation before the randomization code was opened due to failure to follow compliance rules (engaged in a significant change in lifestyle). Consequently, the efficacy statistical analyses were conducted on 74 subjects ( 38 subjects in the KPE group and 36 subjects in the placebo group). The baseline characteristics of the subjects are shown in Table 2. No significant differences in baseline parameters were observed between the KPE and placebo groups. Table 3 shows daily average values for parameters associated with energy intake and physical activity. No significant differences in any of these parameters were observed between the two groups throughout the study.
Table 2 Characteristics of the subjects at baseline

\begin{tabular}{|c|c|c|}
\hline Characteristics & $\begin{array}{l}\text { Placebo group } \\
(n=38)\end{array}$ & $\begin{array}{l}\text { KPE group } \\
(n=38)\end{array}$ \\
\hline Age (years) & $49.5 \pm 9.3$ & $50.2 \pm 8.0$ \\
\hline Height (cm) & $159.45 \pm 6.28$ & $159.0 \pm 8.28$ \\
\hline Body weight (kg) & $69.01 \pm 5.44$ & $68.8 I \pm 7.21$ \\
\hline BMI $\left(k g / m^{2}\right)$ & $27.14 \pm 1.47$ & $27.19 \pm 1.42$ \\
\hline Waist circumference $(\mathrm{cm})$ & $94.27 \pm 5.67$ & $94.38 \pm 5.51$ \\
\hline SBP $(\mathrm{mmHg})$ & $125.0 \pm 14.9$ & $127.0 \pm 13.1$ \\
\hline $\mathrm{DBP}(\mathrm{mmHg})$ & $76.1 \pm 10.8$ & $75.9 \pm 9.1$ \\
\hline HR (bpm) & $68.0 \pm 10.3$ & $66.7 \pm 7.4$ \\
\hline \multicolumn{3}{|l|}{ Abdominal fat area } \\
\hline Visceral $\left(\mathrm{cm}^{2}\right)$ & $90.30 \pm 19.45$ & $90.23 \pm 19.22$ \\
\hline Subcutaneous $\left(\mathrm{cm}^{2}\right)$ & $258.13 \pm 72.16$ & $257.30 \pm 69.43$ \\
\hline Total $\left(\mathrm{cm}^{2}\right)$ & $348.43 \pm 71.63$ & $347.54 \pm 70.95$ \\
\hline \multicolumn{3}{|l|}{ Cholesterol } \\
\hline Total-Cho (mg/dL) & $221.4 \pm 28.4$ & $219.7 \pm 26.4$ \\
\hline HDL-Cho (mg/dL) & $71.4 \pm 14.2$ & $68.8 \pm 15.5$ \\
\hline LDL-Cho (mg/dL) & $139.0 \pm 29.3$ & $137.7 \pm 25.4$ \\
\hline
\end{tabular}

Notes: Values are presented as mean \pm SD. There were no significant differences between the groups.

Abbreviations: BMI, body mass index; bpm, beats per minute; Cho, cholesterol; DBP, diastolic blood pressure; HDL, high-density lipoprotein; HR, heart rate; KPE, Kaempferia parviflora extract; LDL, low-density lipoprotein; SBP, systolic blood pressure.

The rate of test food intake was $99.6 \%(94.0 \%-100.0 \%)$ for the KPE group and $99.5 \%(92.9 \%-100.0 \%)$ for the placebo group, with no between-group differences $(p=0.89)$.

Figure 2 shows changes in VFA, SFA, and TFA compared with baseline. Changes in VFA were $-3.67 \pm 9.20$ and $0.50 \pm 8.62 \mathrm{~cm}^{2}$ in the KPE group and placebo group, respectively. Changes in SFA were $-7.79 \pm 19.69$ and $4.21 \pm 21.42 \mathrm{~cm}^{2}$ in the KPE group and placebo group, respectively. Changes in TFA were $-11.46 \pm 23.38$ and $4.71 \pm 25.84 \mathrm{~cm}^{2}$ in the KPE group and placebo group, respectively. The decrease in VFA, SFA, and TFA at $12 \mathrm{~W}$ in the KPE group was significantly greater than that in the placebo group. The result of repeated measures ANOVA indicated a significant group effect in terms of TFA $(p=0.028)$ and a significant time-by-group interaction between SFA and TFA ( $p=0.038$ and $p=0.038$ ), respectively. The results of assessments of physical parameters (body weight, BMI, and lipid and glucose metabolism blood parameters) are shown in Table 4. FBG was higher in the KPE group compared with the placebo group at $0 \mathrm{~W}$. The change in $F B G$ from $0 \mathrm{~W}$ was significantly lower at $12 \mathrm{~W}$ in the KPE group compared with the placebo group. Moreover, the decrease in TGs in the KPE group was significantly greater than that observed in the placebo group after $12 \mathrm{~W}$. There were no significant differences between the two groups in terms of the other parameters. 
Table 3 Changes in energy intake and physical activity after daily intake of test foods

\begin{tabular}{llllll}
\hline Measurements & Group & $\mathbf{0}$ weeks & $\mathbf{4}$ weeks & $\mathbf{8}$ weeks & 12 weeks \\
\hline Energy intake (kcal) & Placebo & $1760.3 \pm 3 \mid 1.8$ & $1787.5 \pm 379.8$ & $1765.2 \pm 343.8$ & $1690.6 \pm 359.7$ \\
& KPE & $1745.2 \pm 331.4$ & $1737.5 \pm 341.6$ & $1711.4 \pm 370.4$ & $1672.5 \pm 338.6$ \\
Steps (number) & Placebo & $7300.9 \pm 2953.1$ & $8194.6 \pm 3254.3$ & $8021.2 \pm 3761.7$ & $8145.8 \pm 4195.2$ \\
& KPE & $6620.2 \pm 3929.0$ & $7558.2 \pm 4048.6$ & $7568.5 \pm 3915.5$ & $8083.1 \pm 4020.7$ \\
\hline
\end{tabular}

Notes: Data are presented as mean $\pm S D$. There were no significant differences between the groups. Energy intake was calculated based on the meal survey. The start of intake is represented as 0 weeks.

Abbreviation: KPE, Kaempferia parviflora extract.

A

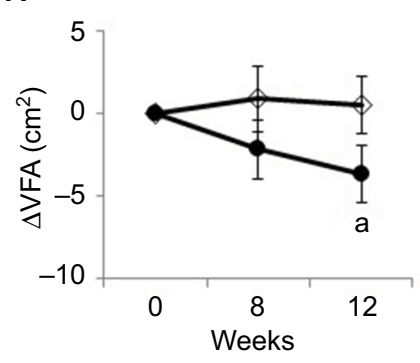

B

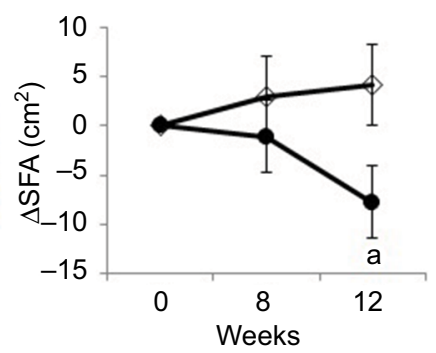

C

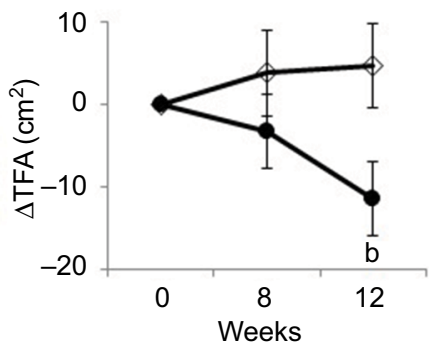

Figure 2 Changes in abdominal fat area after daily intake of test food.

Notes: Values are presented as mean \pm standard error. Changes in VFA (A), SFA (B), and TFA (C) are shown as closed circles (KPE group) and open diamonds (Placebo group). Significant differences are observed between the groups $\left({ }^{\mathrm{a}} p<0.05 ;{ }^{b} p<0.0 \mathrm{I}\right)$.

Abbreviations: KPE, Kaempferia parviflora extract; SFA, subcutaneous fat area; TFA, total fat area; VFA, visceral fat area.

We also performed subgroup analyses of healthy subjects corresponding to BMI $\geq 24$ and $<30 \mathrm{~kg} / \mathrm{m}^{2}$, TGs $<150 \mathrm{mg} / \mathrm{dL}$, HDL-Cho $\geq 40 \mathrm{mg} / \mathrm{dL}, \mathrm{SBP}<140 \mathrm{mmHg}$, DBP $<90 \mathrm{mmHg}$, and FBG $\leq 125 \mathrm{mg} / \mathrm{dL}$. Table 5 shows the changes in physical parameters after daily intake of the test food in these healthy subjects. Healthy subjects who ingested KPE exhibited significantly greater decreases in VFA, SFA, and TFA compared with healthy subjects who ingested the placebo. Moreover, no significant difference in TGs was observed between the placebo and KPE groups at $0 \mathrm{~W}$, but the KPE group exhibited a greater decrease in TGs levels at $12 \mathrm{~W}$ compared with the placebo group.

The safety of KPE was evaluated in the 76 subjects participated in this study (analysis of ITT). Table 6 shows the changes in physical assessment parameters in the safety evaluation. There were no significant differences observed between groups in terms of physical parameters (SBP, DBP, and HR).

Tables 7 and 8 show the results of biochemical analyses. Significant differences in K levels were observed between the two groups at all time points except $0 \mathrm{~W}$, but all values were within the reference range. Significant differences in $\mathrm{Cl}$ levels were observed between the two groups at $0 \mathrm{~W}$. No significant differences in any other parameters were observed between the two groups throughout the study. Values of all biochemical parameters were within the range of physiologic variation. Table 9 shows the results of hematologic analyses. There were no significant differences in any of the hematologic parameters between the two groups at any time point, and values of all hematologic parameters were within reference ranges.

The following adverse events were recorded in the KPE group: common cold in six cases; abdominal pain in two cases; and influenza, zinc deficiency, menopause, tooth ache, and cystitis in one case each. Adverse events reported in the placebo group included common cold in two cases and influenza, allergy to pollen, chest pain, herpes zoster, abdominal pain, and constipation in one case each. All adverse events reported involved symptoms that could have occurred regardless of participation in this study. The adverse events were transient, and there was no observed aggravation due to continuous ingestion of the test food in either group. There were no clinically problematic abnormalities or findings resulting from the physical assessments (Table 6), biochemical and hematologic analyses (Tables 7-9), urinalysis (Table 10), or medical interview conducted by the investigator, which included auscultation and percussion.

\section{Discussion}

In the present study, we evaluated the effect of continual KPE ingestion for 12 weeks in reducing abdominal fat in subjects with a $B M I \geq 24$ and $<30 \mathrm{~kg} / \mathrm{m}^{2}$ via an inventional trial without 
Table 4 Changes in physical parameters after daily intake of test food

\begin{tabular}{|c|c|c|c|c|c|c|}
\hline Measurements & Group & & 0 weeks & 4 weeks & 8 weeks & 12 weeks \\
\hline \multirow[t]{4}{*}{ Body weight (kg) } & Placebo & Values & $69.12 \pm 5.54$ & $69.14 \pm 5.47$ & $68.89 \pm 5.42$ & $68.86 \pm 5.57$ \\
\hline & & $\Delta$ & & $0.02 \pm 0.60$ & $-0.22 \pm 0.91$ & $-0.26 \pm 0.96$ \\
\hline & KPE & Values & $68.63 \pm 7.14$ & $68.63 \pm 7.24$ & $68.33 \pm 7.16$ & $68.14 \pm 7.18$ \\
\hline & & $\Delta$ & & $0.00 \pm 0.75$ & $-0.54 \pm 0.97$ & $-0.48 \pm 1.13$ \\
\hline \multirow[t]{4}{*}{ BMI $\left(\mathrm{kg} / \mathrm{m}^{2}\right)$} & Placebo & Values & $27.16 \pm 1.52$ & $27.17 \pm 1.57$ & $27.07 \pm 1.56$ & $27.06 \pm 1.58$ \\
\hline & & $\Delta$ & & $0.01 \pm 0.24$ & $-0.09 \pm 0.37$ & $-0.10 \pm 0.37$ \\
\hline & KPE & Values & $27.09 \pm 1.35$ & $27.09 \pm 1.35$ & $26.92 \pm 1.29$ & $26.90 \pm 1.38$ \\
\hline & & $\Delta$ & & $0.01 \pm 0.29$ & $-0.22 \pm 0.38$ & $-0.19 \pm 0.45$ \\
\hline \multirow[t]{4}{*}{ Total-Cho (mg/dL) } & Placebo & Values & $211.9 \pm 29.9$ & $209.4 \pm 27.2$ & $215.6 \pm 28.4$ & $215.1 \pm 28.4$ \\
\hline & & $\Delta$ & & $-2.5 \pm 15.4$ & $3.6 \pm 18.5$ & $3.1 \pm 20.3$ \\
\hline & KPE & Values & $219.2 \pm 25.8$ & $214.3 \pm 24.7$ & $217.1 \pm 26.8$ & $218.9 \pm 28.0$ \\
\hline & & $\Delta$ & & $-4.9 \pm 14.8$ & $-1.9 \pm 18.5$ & $-0.3 \pm 16.0$ \\
\hline \multirow[t]{4}{*}{ HDL-Cho (mg/dL) } & Placebo & Values & $67.7 \pm 14.3$ & $65.6 \pm 14.0$ & $65.7 \pm 14.2$ & $63.1 \pm 13.4$ \\
\hline & & $\Delta$ & & $-2 . I \pm 6.1$ & $-2.0 \pm 6.0$ & $-4.6 \pm 6.2$ \\
\hline & KPE & Values & $67.6 \pm 16.2$ & $65.3 \pm 15.2$ & $64.3 \pm 15.8$ & $63.1 \pm 13.7$ \\
\hline & & $\Delta$ & & $-2.2 \pm 5.5$ & $-3.0 \pm 7.7$ & $-4.5 \pm 6.5$ \\
\hline \multirow[t]{4}{*}{ LDL-Cho (mg/dL) } & Placebo & Values & $130.5 \pm 26.4$ & $127.1 \pm 27.6$ & $133.9 \pm 30.6$ & $132.2 \pm 25.5$ \\
\hline & & $\Delta$ & & $-3.4 \pm 15.4$ & $3.4 \pm 18.0$ & $1.7 \pm 16.9$ \\
\hline & KPE & Values & $135.9 \pm 24.9$ & $132.0 \pm 22.2$ & $134.5 \pm 25.3$ & $133.8 \pm 25.2$ \\
\hline & & $\Delta$ & & $-3.9 \pm 11.9$ & $-1.5 \pm 16.4$ & $-2.1 \pm 13.2$ \\
\hline \multirow[t]{4}{*}{ TGs (mg/dL) } & Placebo & Values & $83.2 \pm 35.5$ & $86.9 \pm 31.7$ & $90.0 \pm 40.7$ & $88.4 \pm 32.3$ \\
\hline & & $\Delta$ & & $3.7 \pm 27.4$ & $6.8 \pm 35.8$ & $5.2 \pm 21.9$ \\
\hline & KPE & Values & $102.6 \pm 67.0$ & $91.6 \pm 36.9$ & $98.5 \pm 57.7$ & $92.3 \pm 54.9$ \\
\hline & & $\Delta$ & & $-10.9 \pm 45.7$ & $-5.6 \pm 29.5$ & $-10.3 \pm 37.8^{a}$ \\
\hline \multirow[t]{4}{*}{$\mathrm{FBG}(\mathrm{mg} / \mathrm{dL})$} & Placebo & Values & $85.7 \pm 7.3$ & $86.5 \pm 7.3$ & $86.5 \pm 7.7$ & $88.6 \pm 9.2$ \\
\hline & & $\Delta$ & & $0.8 \pm 4.9$ & $0.8 \pm 6.2$ & $2.9 \pm 6.6$ \\
\hline & KPE & Values & $89.2 \pm 7.3^{\mathrm{a}}$ & $87.7 \pm 6.8$ & $88.9 \pm 7.1$ & $88.9 \pm 7.9$ \\
\hline & & $\Delta$ & & $-1.5 \pm 4.9^{a}$ & $-0.4 \pm 6.0$ & $-0.3 \pm 5.3^{\mathrm{a}}$ \\
\hline \multirow[t]{4}{*}{ HbAlc (\%) } & Placebo & Values & $5.39 \pm 0.33$ & Not measured & Not measured & $5.44 \pm 0.32$ \\
\hline & & $\Delta$ & & & & $0.06 \pm 0.15$ \\
\hline & KPE & Values & $5.44 \pm 0.26$ & Not measured & Not measured & $5.48 \pm 0.25$ \\
\hline & & $\Delta$ & & & & $0.04 \pm 0.19$ \\
\hline
\end{tabular}

Notes: Values are presented as mean \pm SD. Changes from the start of intake ( 0 weeks) are represented as delta $(\Delta)$. There were significant differences for the placebo group according to the Student's $t$-test $\left({ }^{\mathrm{a}} \mathrm{P}<0.05\right)$.

Abbreviations: BMI, body mass index; Cho, cholesterol; FBG, fasting blood glucose; HbAlc, hemoglobin Alc; HDL, high-density lipoprotein; KPE, Kaempferia parviflora extract; LDL, low-density lipoprotein; TGs, triglycerides.

change in lifestyle. We found that VFA decreased significantly in the KPE group compared with the placebo group after 12W. SFA, TFA, and TGs also decreased significantly in the KPE group after $12 \mathrm{~W}$ compared with the placebo group. The subjects were instructed to maintain their usual eating, exercise, sleeping, smoking, and drinking habits during the study period. Indeed, energy intake and physical activity did not differ between the two groups throughout the study. As the only difference between the active and placebo test food capsules was the presence of KPE, the results of our study indicate that ingestion of KPE reduces abdominal fat in overweight and preobese subjects with a BMI $\geq 24$ and $<30 \mathrm{~kg} /$ $\mathrm{m}^{2}$, ruling out changes in energy intake and physical activity as causing the observed effects. It was previously reported that seasonal variations in food intake, physical activity, and body weight can affect VFA, SFA, and TFA..$^{28,29}$ However, in the present study, no differences were observed compared with baseline values ( $0 \mathrm{~W}$ ) in terms of VFA, SFA, TFA, body weight, and BMI in the placebo group. Seasonal variation thus appears to have had little influence on the results.

The results of previous rodent and in vitro studies suggested that KPE and polymethoxyflavone reduce levels of body fat. ${ }^{19-23}$ Hence, we hypothesize that the effect of KPE in reducing abdominal fat in this study is mainly due to polymethoxyflavone contained in the KPE.

Because obesity develops when energy intake exceeds energy expenditure, reducing energy intake and accelerating energy expenditure are considered important strategies for 
Table 5 Changes in physical parameters in healthy subjects (excluding subjects with dyslipidemia, hypertension, and hyperglycemia)

\begin{tabular}{|c|c|c|c|c|c|c|}
\hline Measurements & Group & & 0 weeks & 4 weeks & 8 weeks & 12 weeks \\
\hline \multirow[t]{4}{*}{ Body weight (kg) } & Placebo & Values & $69.78 \pm 5.65$ & $69.76 \pm 5.62$ & $69.48 \pm 28.4$ & $69.55 \pm 5.76$ \\
\hline & & $\Delta$ & & $-0.01 \pm 0.11$ & $-0.29 \pm 0.16$ & $-0.22 \pm 0.19$ \\
\hline & KPE & Values & $66.35 \pm 6.45^{\mathrm{a}}$ & $66.42 \pm 6.45$ & $66.18 \pm 6.55$ & $65.92 \pm 6.44^{\mathrm{a}}$ \\
\hline & & $\Delta$ & & $0.07 \pm 0.15$ & $-0.46 \pm 0.23$ & $-0.44 \pm 0.25$ \\
\hline \multirow[t]{4}{*}{ BMI $\left(\mathrm{kg} / \mathrm{m}^{2}\right)$} & Placebo & Values & $27.43 \pm 1.37$ & $27.43 \pm 1.43$ & $27.3 I \pm I .40$ & $27.35 \pm 1.45$ \\
\hline & & $\Delta$ & & $0.00 \pm 0.05$ & $-0.12 \pm 0.06$ & $-0.09 \pm 0.07$ \\
\hline & KPE & Values & $27.09 \pm 1.45$ & $27.13 \pm 1.45$ & $26.99 \pm 1.34$ & $26.91 \pm 1.47$ \\
\hline & & $\Delta$ & & $0.04 \pm 0.06$ & $-0.20 \pm 0.09$ & $-0.18 \pm 0.10$ \\
\hline \multirow[t]{4}{*}{ VFA $\left(\mathrm{cm}^{2}\right)$} & Placebo & Values & $88.33 \pm 20.78$ & Not measured & $88.55 \pm 21.95$ & $89.08 \pm 19.18$ \\
\hline & & $\Delta$ & & & $0.22 \pm 1.85$ & $0.75 \pm 1.77$ \\
\hline & KPE & Values & $84.72 \pm 18.26$ & Not measured & $83.32 \pm 18.06$ & $80.42 \pm 18.30$ \\
\hline & & $\Delta$ & & & $-2.17 \pm 1.70$ & $-4.30 \pm 1.40^{\mathrm{a}}$ \\
\hline \multirow[t]{4}{*}{ SFA $\left(\mathrm{cm}^{2}\right)$} & Placebo & Values & $276.21 \pm 68.29$ & Not measured & $277.29 \pm 73.74$ & $279.57 \pm 73.72$ \\
\hline & & $\Delta$ & & & $1.08 \pm 4.20$ & $3.36 \pm 4.40$ \\
\hline & KPE & Values & $263.96 \pm 67.76$ & Not measured & $267.96 \pm 63.89$ & $254.43 \pm 59.5$ I \\
\hline & & $\Delta$ & & & $2.02 \pm 4.74$ & $-9.53 \pm 4.56^{\mathrm{a}}$ \\
\hline \multirow[t]{4}{*}{ TFA $\left(m^{2}\right)$} & Placebo & Values & $364.54 \pm 72.51$ & Not measured & $365.84 \pm 81.04$ & $368.65 \pm 78.20$ \\
\hline & & $\Delta$ & & & $1.30 \pm 5.00$ & $4.11 \pm 5.39$ \\
\hline & KPE & Values & $348.68 \pm 71.67$ & Not measured & $351.28 \pm 64.90$ & $334.85 \pm 62.79$ \\
\hline & & $\Delta$ & & & $-0.15 \pm 5.78$ & $-13.83 \pm 5.13^{a}$ \\
\hline \multirow[t]{4}{*}{ TGs (mg/dL) } & Placebo & Values & $75.46 \pm 23.67$ & $81.36 \pm 24.56$ & $87.54 \pm 41.53$ & $85.11 \pm 29.16$ \\
\hline & & $\Delta$ & & $5.89 \pm 3.77$ & $12.07 \pm 5.72$ & $9.64 \pm 3.59$ \\
\hline & KPE & Values & $70.83 \pm 21.30$ & $79.38 \pm 27.13$ & $74.26 \pm 25.54$ & $69.21 \pm 24.59^{\mathrm{a}}$ \\
\hline & & $\Delta$ & & $8.54 \pm 4.66$ & $2.43 \pm 3.57$ & $-1.63 \pm 4.71$ \\
\hline
\end{tabular}

Notes: Values are presented as mean $\pm S D$. There were significant differences from the placebo group according to the Student's $t$-test ( ${ }^{a} p<0.05$ ).

Abbreviations: BMI, body mass index; KPE, Kaempferia parviflora extract; SFA, subcutaneous fat area; TFA, total fat area; TGs, triglycerides; VFA, visceral fat area.

Table 6 Changes in blood pressure and heart rate after daily intake of test food

\begin{tabular}{llllll}
\hline Measurements & Group & 0 weeks & 4 weeks & 8 weeks & I2 weeks \\
\hline SBP $(\mathrm{mmHg})$ & Placebo & $123.9 \pm I 5.1$ & $120.4 \pm 16.0$ & $122.5 \pm 15.9$ & $117.5 \pm 14.0$ \\
& KPE & $125.7 \pm 10.7$ & $120.8 \pm 12.7$ & $124.0 \pm 14.1$ & $118.3 \pm I 1.7$ \\
DBP $(\mathrm{mmHg})$ & Placebo & $74.9 \pm 11.6$ & $71.6 \pm 12.8$ & $73.3 \pm \mid 1.7$ & $68.8 \pm I 1.4$ \\
& KPE & $74.6 \pm 9.0$ & $70.8 \pm 9.2$ & $72.3 \pm 9.2$ & $67.7 \pm 10.8$ \\
HR $(\mathrm{bPm})$ & Placebo & $67.2 \pm 9.1$ & $68.0 \pm 8.5$ & $66.3 \pm 8.2$ & $71.3 \pm 8.9$ \\
& KPE & $66.1 \pm 7.6$ & $67.1 \pm 7.3$ & $66.4 \pm 7.7$ & $70.0 \pm 8.1$ \\
\hline
\end{tabular}

Notes: Values are presented as the mean \pm SD. There were no significant differences between the groups.

Abbreviations: bpm, beats per minute; DBP, diastolic blood pressure; HR, heart rate; KPE, Kaempferia parviflora extract; SBP, systolic blood pressure.

preventing obesity. ${ }^{3}$ Some food ingredients reportedly modulate energy intake and energy expenditure in humans. For example, indigestible dextrin reportedly inhibits lipid absorption, and capsinoids accelerate energy expenditure. ${ }^{30-32}$ In the present study, ingestion of KPE did not result in a change in energy intake during the ingestion period, which suggests that the anti-obesity effects of KPE involve acceleration of energy expenditure rather than inhibition of energy intake. Indeed, we previously reported that KPE enhances energy expenditure in mice via activation of sympathetic nerve activity. ${ }^{23}$ Others reported that one intake of KPE increases wholebody energy expenditure in humans. ${ }^{24}$ Hence, a KPE-induced increase in energy expenditure could have contributed to the observed reduction in abdominal fat in our study.

Obesity is associated with metabolic disorders such as hypertension, diabetes mellitus, and atherosclerosis, which are risk factors for coronary artery disease..$^{1-3} \mathrm{~A}$ number of studies have reported that body fat distribution is closely linked with risk of developing metabolic disorders, and an excess of abdominal fat, especially abdominal visceral fat, can lead to these disorders, irrespective of body weight. ${ }^{33-35}$ Accordingly, reducing body fat, especially visceral fat, is critical for the prevention of metabolic disorders. Our results indicate that KPE reduces TFA by reducing VFA. Therefore, KPE may be 
Table 7 Changes in biochemical parameters after daily intake of test food

\begin{tabular}{|c|c|c|c|c|c|c|}
\hline Measurements & Standard range & Group & 0 weeks & 4 weeks & 8 weeks & I 2 weeks \\
\hline \multirow[t]{2}{*}{$\mathrm{TP}(\mathrm{g} / \mathrm{dL})$} & $6.7-8.3$ & Placebo & $7.40 \pm 0.28$ & $7.32 \pm 0.28$ & $7.4 I \pm 0.34$ & $7.25 \pm 0.32$ \\
\hline & & KPE & $7.53 \pm 0.37$ & $7.43 \pm 0.40$ & $7.45 \pm 0.35$ & $7.35 \pm 0.37$ \\
\hline \multirow[t]{2}{*}{ Albumin (g/dL) } & $3.8-5.2$ & Placebo & $4.38 \pm 0.27$ & $4.25 \pm 0.21$ & $4.22 \pm 0.24$ & $4.17 \pm 0.24$ \\
\hline & & KPE & $4.42 \pm 0.27$ & $4.28 \pm 0.22$ & $4.27 \pm 0.25$ & $4.17 \pm 0.25$ \\
\hline \multirow[t]{2}{*}{ T-bil (mg/dL) } & $0.3-1.2$ & Placebo & $0.76 \pm 0.26$ & $0.78 \pm 0.26$ & $0.74 \pm 0.27$ & $0.78 \pm 0.28$ \\
\hline & & KPE & $0.78 \pm 0.26$ & $0.78 \pm 0.28$ & $0.80 \pm 0.26$ & $0.80 \pm 0.26$ \\
\hline \multirow[t]{2}{*}{ AST (U/L) } & $10-40$ & Placebo & $21.6 \pm 4.4$ & $21.0 \pm 4.6$ & $21.9 \pm 5.5$ & $21.0 \pm 4.1$ \\
\hline & & KPE & $20.7 \pm 4.5$ & $20.5 \pm 4.8$ & $21.0 \pm 4.9$ & $20.4 \pm 4.7$ \\
\hline \multirow[t]{2}{*}{$\mathrm{ALT}(\mathrm{U} / \mathrm{L})$} & $5-40$ & Placebo & $22.3 \pm 9.3$ & $21.4 \pm 9.2$ & $22.8 \pm 10.5$ & $21.1 \pm 9.6$ \\
\hline & & KPE & $20.4 \pm 7.3$ & $21.9 \pm 12.7$ & $19.8 \pm 7.2$ & $18.9 \pm 8.3$ \\
\hline \multirow[t]{2}{*}{$\gamma-\mathrm{GTP}(\mathrm{U} / \mathrm{L})$} & M: 70 & Placebo & $29.2 \pm 22.3$ & $30.2 \pm 30.3$ & $29.7 \pm 23.5$ & $28.6 \pm 21.7$ \\
\hline & $\mathrm{F}: 30$ & KPE & $26.1 \pm 16.3$ & $27.0 \pm 18.8$ & $24.4 \pm 15.7$ & $24.6 \pm 17.3$ \\
\hline \multirow[t]{2}{*}{ LDH (U/L) } & $115-245$ & Placebo & $179.8 \pm 29.4$ & $180.9 \pm 30.0$ & $183.5 \pm 35.1$ & $186.5 \pm 28.6$ \\
\hline & & KPE & $182.9 \pm 28.6$ & $181.7 \pm 30.3$ & $180.4 \pm 30.5$ & $196.0 \pm 30.9$ \\
\hline \multirow[t]{2}{*}{ ALP (U/L) } & $115-359$ & Placebo & $198.2 \pm 42.4$ & $196.1 \pm 46.9$ & $193.4 \pm 42.4$ & $191.8 \pm 46.5$ \\
\hline & & KPE & $211.7 \pm 68.4$ & $208.4 \pm 65.5$ & $203.7 \pm 59.8$ & $201.1 \pm 63.2$ \\
\hline \multirow[t]{2}{*}{ Uric acid (mg/dL) } & M: $3.7-7.0$ & Placebo & $4.96 \pm 1.31$ & $5.07 \pm 1.39$ & $5.29 \pm 1.31$ & $5.16 \pm 1.43$ \\
\hline & F: $2.5-7.0$ & KPE & $4.91 \pm 1.22$ & $5.06 \pm 1.46$ & $4.99 \pm 1.13$ & $4.99 \pm 1.12$ \\
\hline \multirow[t]{2}{*}{ BUN (mg/dL) } & $8.0-22.0$ & Placebo & $13.16 \pm 3.35$ & $12.92 \pm 3.20$ & $13.69 \pm 3.29$ & $13.72 \pm 3.24$ \\
\hline & & KPE & $11.99 \pm 3.42$ & $13.10 \pm 3.42$ & $12.52 \pm 3.05$ & $|2.4| \pm 3.74$ \\
\hline \multirow[t]{2}{*}{ Creatinine $(\mathrm{mg} / \mathrm{dL})$} & $M: 0.61-1.04$ & Placebo & $0.642 \pm 0.098$ & $0.625 \pm 0.113$ & $0.677 \pm 0.085$ & $0.664 \pm 0.090$ \\
\hline & F: $0.47-0.79$ & KPE & $0.65 \mathrm{I} \pm 0.144$ & $0.637 \pm 0.151$ & $0.677 \pm 0.145$ & $0.674 \pm 0.140$ \\
\hline
\end{tabular}

Notes: Values are presented as mean \pm SD. There were no significant differences between the groups.

Abbreviations: ALP, alkaline phosphatase; ALT, alanine aminotransferase; AST, aspartate aminotransferase; BUN, blood urea nitrogen; $\gamma$-GTP, $\gamma$-glutamyltranspeptidase; KPE, Kaempferia parviflora extract; LDH, lactate dehydrogenase; T-bil, total bilirubin; TP, total protein.

Table 8 Changes in blood electrolyte levels after daily intake of test food

\begin{tabular}{lllllll}
\hline Measurements & Standard range & Group & 0 weeks & 4 weeks & $\mathbf{8}$ weeks & I2 weeks \\
\hline $\mathrm{Na}(\mathrm{mEq} / \mathrm{L})$ & $136-147$ & Placebo & $140.4 \pm 1.5$ & $140.6 \pm 1.5$ & $140.3 \pm 1.6$ & $140.4 \pm 1.3$ \\
& & KPE & $140.5 \pm 1.9$ & $140.4 \pm 2.0$ & $139.9 \pm 1.7$ & $140.5 \pm 1.7$ \\
$\mathrm{~K}(\mathrm{mEq} / \mathrm{L})$ & $3.6-5.0$ & Placebo & $4.04 \pm 0.28$ & $4.04 \pm 0.24$ & $4.13 \pm 0.29$ & $3.99 \pm 0.25$ \\
& & KPE & $3.98 \pm 0.28$ & $3.90 \pm 0.25^{\mathrm{a}}$ & $3.97 \pm 0.2 \mathrm{I}^{\mathrm{b}}$ & $3.85 \pm 0.24^{\mathrm{a}}$ \\
$\mathrm{Cl}(\mathrm{mEq} / \mathrm{L})$ & $98-109$ & Placebo & $103.8 \pm 1.5$ & $103.9 \pm 1.5$ & $104.0 \pm 1.5$ & $105.0 \pm 1.7$ \\
& & KPE & $102.9 \pm 2.0^{\mathrm{a}}$ & $103.3 \pm 2.1$ & $103.5 \pm 1.9$ & $104.5 \pm 1.8$ \\
$\mathrm{Ca}(\mathrm{mg} / \mathrm{L})$ & $8.5-10.2$ & Placebo & $9.19 \pm 0.27$ & $9.19 \pm 0.30$ & $9.36 \pm 0.23$ & $9.26 \pm 0.24$ \\
& & KPE & $9.30 \pm 0.24$ & $9.28 \pm 0.25$ & $9.40 \pm 0.26$ & $9.23 \pm 0.21$ \\
$\mathrm{Mg}(\mathrm{mg} / \mathrm{L})$ & $1.8-2.6$ & Placebo & $2.22 \pm 0.14$ & $2.16 \pm 0.12$ & $2.22 \pm 0.13$ & $2.19 \pm 0.14$ \\
& & KPE & $2.21 \pm 0.14$ & $2.18 \pm 0.14$ & $2.23 \pm 0.13$ & $2.20 \pm 0.14$ \\
$\mathrm{Fe}(\mu \mathrm{g} / \mathrm{L})$ & $\mathrm{M}: 54-200$ & Placebo & $116.8 \pm 43.5$ & $114.1 \pm 44.8$ & $107.6 \pm 38.1$ & $109.0 \pm 40.8$ \\
& F: $48-154$ & KPE & $107.5 \pm 25.8$ & $109.3 \pm 38.3$ & $114.7 \pm 43.3$ & $100.2 \pm 34.1$ \\
\hline
\end{tabular}

Notes: Values are presented as mean \pm SD. There were significant differences between the groups $\left({ }^{a} p<0.05 ;{ }^{b} p<0.01\right)$.

Abbreviations: $\mathrm{Ca}$, calcium; $\mathrm{Cl}$, chloride; Fe, iron; K, potassium; KPE, Kaempferia parviflora extract; Mg, magnesium; Na, sodium.

useful for preventing obesity as well as reducing the risk of metabolic disorders and coronary artery disease. The improvements in lipid metabolism, such as a reduction of TGs and an increase of HDL-Cho, reduce the risk of cardiovascular diseases. Indeed, fibrates are used to lower elevated TGs and raise HDL-Cho levels. Previous studies have shown that fibrates reduce cardiovascular diseases. ${ }^{36}$ Although no significant differences in HDL-Cho and LDL-Cho levels were observed in this study, KPE significantly decreased serum TGs. Therefore, daily intake of KPE may prevent and/or reduce the risk of cardiovascular diseases via improvements in lipid metabolism.

Adipomyokines such as leptin, adiponectin, and irisin and gut hormones such as ghrelin and glucagon-like peptide-1 play important roles in maintaining energy homeostasis. . $^{37,38}$ Imbalances in the circulating levels of these hormones are reportedly related to metabolic disorder development, ${ }^{37,39}$ and 
Table 9 Changes in hematologic parameters after daily intake of test food

\begin{tabular}{|c|c|c|c|c|c|c|}
\hline Measurements & Standard range & Group & 0 weeks & 4 weeks & 8 weeks & I 2 weeks \\
\hline \multirow[t]{2}{*}{$\mathrm{WBC}(/ \mu \mathrm{L})$} & M: 3900-9800 & Placebo & $5666 \pm 1425$ & $5627 \pm|29|$ & $5459 \pm 1242$ & $5670 \pm 1262$ \\
\hline & F: $3500-9100$ & KPE & $5595 \pm 1359$ & $5634 \pm|4| 4$ & $5670 \pm 1474$ & $5800 \pm 1562$ \\
\hline \multirow[t]{2}{*}{$\mathrm{RBC}\left(\times 10^{4} / \mu \mathrm{L}\right)$} & M: 427-570 & Placebo & $463.2 \pm 25.4$ & $465.5 \pm 27.0$ & $468.1 \pm 28.2$ & $460.0 \pm 27.7$ \\
\hline & F: $376-500$ & KPE & $465.4 \pm 46.3$ & $458.1 \pm 46.8$ & $47 I .7 \pm 43.7$ & $456.9 \pm 45.0$ \\
\hline \multirow[t]{2}{*}{$\mathrm{Hb}(\mathrm{g} / \mathrm{dL})$} & M: I3.5-17.6 & Placebo & $13.61 \pm 1.15$ & $13.46 \pm 1.20$ & $13.86 \pm 1.35$ & $13.61 \pm 1.33$ \\
\hline & F: $11.3-15.2$ & KPE & $13.56 \pm 1.15$ & $13.38 \pm 1.07$ & $13.83 \pm 1.15$ & $13.36 \pm 1.17$ \\
\hline \multirow[t]{2}{*}{$\mathrm{Ht}(\%)$} & M: 39.8-5I.8 & Placebo & $42.28 \pm 2.86$ & $42.12 \pm 3.21$ & $43.09 \pm 3.54$ & $43.01 \pm 3.48$ \\
\hline & F: $33.4-44.9$ & KPE & $42.14 \pm 3.31$ & $41.89 \pm 3.08$ & $42.89 \pm 3.16$ & $42.35 \pm 3.27$ \\
\hline \multirow[t]{2}{*}{ Plts $\left(\times 10^{4} / \mu \mathrm{L}\right)$} & $M:|3|-36.2$. & Placebo & $27.29 \pm 5.35$ & $27.57 \pm 4.76$ & $27.10 \pm 4.56$ & $26.60 \pm 5.56$ \\
\hline & F: $13.0-36.9$ & KPE & $27.88 \pm 5.01$ & $27.09 \pm 5.59$ & $27.33 \pm 5.53$ & $26.78 \pm 5.78$ \\
\hline \multirow[t]{2}{*}{$M C V(f L)$} & M: 82.7-101.6 & Placebo & $91.32 \pm 4.73$ & $92.29 \pm 4.93$ & $92.05 \pm 5.10$ & $93.46 \pm 4.76$ \\
\hline & F: $79.0-100.0$ & KPE & $90.86 \pm 4.70$ & $91.80 \pm 4.79$ & $91.19 \pm 4.65$ & $92.99 \pm 4.79$ \\
\hline \multirow[t]{2}{*}{$\mathrm{MCH}(\mathrm{pg})$} & M: 28.0-34.6 & Placebo & $29.37 \pm 1.91$ & $29.49 \pm 1.90$ & $29.59 \pm 1.97$ & $29.56 \pm 1.98$ \\
\hline & F: $26.3-34.3$ & KPE & $29.22 \pm 1.54$ & $29.31 \pm 1.56$ & $29.38 \pm 1.59$ & $29.33 \pm 1.62$ \\
\hline \multirow[t]{2}{*}{$\mathrm{MCHC}(\%)$} & M: 31.6-36.6 & Placebo & $32.15 \pm 0.91$ & $31.94 \pm 0.89$ & $32.15 \pm 0.90$ & $31.62 \pm 1.20$ \\
\hline & F: $30.7-36.6$ & $\mathrm{KPE}$ & $32.17 \pm 0.62$ & $31.93 \pm 0.69$ & $32.22 \pm 0.67$ & $31.53 \pm 0.102$ \\
\hline
\end{tabular}

Notes: Values are presented as mean \pm SD. There were no significant differences between the groups.

Abbreviations: F, female; Hb, hemoglobin; $\mathrm{Ht}$, hematocrit; KPE, Kaempferia parviflora extract; M, male; $\mathrm{MCH}$, mean corpuscular hemoglobin; MCHC, mean corpuscular hemoglobin concentration; MCV, mean corpuscular volume; Plts, platelets; RBC, red blood cell; WBC, white blood cell.

Table 10 Changes in urinalysis parameters after daily intake of test food

\begin{tabular}{|c|c|c|c|c|c|c|c|c|c|c|c|c|}
\hline \multirow[t]{2}{*}{ Measurements } & \multirow{2}{*}{$\begin{array}{l}\text { Standard } \\
\text { range }\end{array}$} & \multirow[t]{2}{*}{ Group } & \multicolumn{5}{|c|}{0 weeks } & \multicolumn{5}{|c|}{12 weeks } \\
\hline & & & - & \pm & + & & & - & \pm & + & & \\
\hline \multirow[t]{2}{*}{ Urine protein } & $(-)$ & Placebo & 34 & 4 & 0 & & & 29 & 8 & 0 & & \\
\hline & & KPE & 34 & 4 & 0 & & & 28 & 9 & I & & \\
\hline \multirow[t]{2}{*}{ Urine glucose } & $(-)$ & Placebo & 38 & 0 & 0 & & & 37 & 0 & 0 & & \\
\hline & & KPE & 38 & 0 & 0 & & & 38 & 0 & 0 & & \\
\hline \multirow[t]{2}{*}{ Urobilinogen } & $( \pm)$ & Placebo & 0 & 38 & 0 & & & 0 & 37 & 0 & & \\
\hline & & KPE & 0 & 38 & 0 & & & 0 & 38 & 0 & & \\
\hline \multirow[t]{3}{*}{ Bilirubin } & $(-)$ & Placebo & 38 & 0 & 0 & & & 37 & 0 & 0 & & \\
\hline & & $\mathrm{KPE}$ & 38 & 0 & 0 & & & 38 & 0 & 0 & & \\
\hline & & & - & \pm & + & $2+$ & $3+$ & - & \pm & + & $2+$ & $3+$ \\
\hline \multirow[t]{2}{*}{ Ketone bodies } & $(-)$ & Placebo & 36 & 0 & 2 & 0 & 0 & 37 & 0 & 0 & 0 & 0 \\
\hline & & KPE & 38 & 0 & 0 & 0 & 0 & 37 & 0 & 0 & I & 0 \\
\hline \multirow[t]{2}{*}{ Occult blood } & $(-)$ & Placebo & 31 & 0 & 3 & I & 3 & 33 & 0 & 2 & I & I \\
\hline & & KPE & 31 & 0 & 5 & 0 & 2 & 34 & 0 & 4 & 0 & 0 \\
\hline \multirow[t]{2}{*}{ Specific gravity } & $1.005-1.030$ & Placebo & \multicolumn{5}{|c|}{$1.0153 \pm 0.0068$} & \multicolumn{5}{|c|}{$1.0183 \pm 0.0072$} \\
\hline & & $\mathrm{KPE}$ & \multicolumn{5}{|c|}{$1.0160 \pm 0.0062$} & \multicolumn{5}{|c|}{$1.0170 \pm 0.008 \mid$} \\
\hline \multirow[t]{2}{*}{$\mathrm{pH}$} & $5.0-7.5$ & Placebo & \multicolumn{5}{|c|}{$6.25 \pm 0.75$} & \multicolumn{5}{|c|}{$6.34 \pm 0.84$} \\
\hline & & KPE & \multicolumn{5}{|c|}{$6.39 \pm 0.70$} & \multicolumn{5}{|c|}{$6.37 \pm 0.66$} \\
\hline
\end{tabular}

Notes: Urine protein, urine glucose, urobilinogen, bilirubin, ketone bodies, and occult blood: values indicate the number of subjects. Status is indicated as follows: -, negative; \pm , false-positive; + , positive (mild); $2+$, positive (moderate); $3+$, positive (serious). Specific gravity and $\mathrm{pH}$ : values are presented as mean \pm SD. There were no significant differences between the groups.

Abbreviation: KPE, Kaempferia parviflora extract.

ingestion of specific foods has a beneficial effect on profiles of these factors. For example, regular consumption of foods and beverages containing catechin compounds increases adiponectin levels in individuals with metabolic syndrome and type 2 diabetes. ${ }^{40}$ It is anticipated that further intensive studies examining the effect of KPE on adipomyokine levels will provide evidence for whether KPE ingestion can prevent the development of metabolic disorders.
It has been reported that KPE is not associated with any pharmacotoxic or histopathological effects in rats. ${ }^{41} \mathrm{As}$ KPE has been reported to be safe in animals, we evaluated the safety of KPE ingestion. In this study, no serious or test foods-related adverse events occurred. Moreover, there were no clinically problematic abnormalities or findings resulting from the physical assessments, biochemical and hematologic analyses, urinalysis, or medical interview 
conducted by the investigator. Therefore, KPE used in this study (150 mg KPE) is considered safe over long-term ingestion.

A potential limitation of this study was its relatively short duration; as such, the potential long-term effects of KPE ingestion remain unknown. As the differences in VFA, SFA, and TFA between the active KPE and placebo groups increased over time and did not plateau by the end of the study, it is possible that the benefits afforded by KPE would increase with longer ingestion. Moreover, despite careful instruction on dietary habits and other lifestyle factors, the changes in total and macronutrient intake and daily physical activity may have differed in the two groups. These between-group differences in compliance outcomes were not significant, but they may have affected the study results.

\section{Conclusion}

The results of the present study indicate that continual ingestion of KPE reduces abdominal fat in healthy humans with a BMI $\geq 24$ and $<30 \mathrm{~kg} / \mathrm{m}^{2}$. KPE could therefore be a useful and safe food for preventing and/or improving obesity and the development of obesity-related metabolic disorders.

\section{Acknowledgments}

The authors would like to thank the volunteers who participated in this study. We acknowledge Ms. Heather Suzuki for substantially contributing to the preparation of the manuscript, Mr. Yoshitaka Hatakeyama who oversaw assignment of the test foods to the study subjects, and Mr Fujio Matsuo who generated randomization codes and created an allocation list. We also gratefully thank the contribution of all the study staff. Maruzen Pharmaceuticals Co. Ltd. sponsored this study.

\section{Author contributions}

All authors contributed toward data analysis, drafting and revising the paper and agree to be accountable for all aspects of the work.

\section{Disclosure}

SY, RA, YM, and HK are employees of Maruzen Pharmaceuticals Co. Ltd. IF was the principal investigator. HS, TA, and ST are employees of New Drug Research Center Inc. The authors report no other conflicts of interest in this work.

\section{References}

1. Kahn BB, Flier JS. Obesity and insulin resistance. J Clin Invest. 2000;106(4):473-481.

2. Mathieu P, Pibarot P, Despres JP. Metabolic syndrome: the danger signal in atherosclerosis. Vasc Health Risk Manag. 2006;2(3):285-302.
3. Eckel RH, Grundy SM, Zimmet PZ. The metabolic syndrome. Lancet. 2005;365(9468):1415-1428.

4. Spiegelman BM, Flier JS. Obesity and the regulation of energy balance. Cell. 2001;104(4):531-543.

5. Hsu IR, Kim SP, Kabir M, Bergman RN. Metabolic syndrome, hyperinsulinemia, and cancer. Am J Clin Nutr. 2007;86(Suppl 3):s867-s871.

6. Frayn KN. Visceral fat and insulin resistance-causative or correlative? Br J Nutr. 2000;83(Suppl 1):S71-S77.

7. Fujita H, Yokoyama K, Yoshikawa M. Classification and antihypertensive activity of angiotensin I-converting enzyme derived from food proteins. J Food Sci. 2000;65(4):564-569.

8. Fujita H, Yamagami T, Ohshima K. Long-term ingestion of a fermented soybean-derived touchi- extract with $\alpha$-glucosidase inhibitory activity is safe and effective in human with borderline and mild type- 2 diabetes. J Nutr. 2001;131(8):2105-2108.

9. Hursel R, Viechtbauer W, Dulloo AG, et al. The effects of catechin rich teas and caffeine on energy expenditure and fat oxidation: a metaanalysis. Obes Rev. 2011;12(7):573-581.

10. Tsuji H, Kasai M, Takeuchi H, Nakamura M, Okazaki M, Kondo K. Dietary medium-chain triacylglycerols suppress accumulation of body fat in a double blind, controlled trial in healthy men and women. $J$ Nutr. 2001;131(11):2853-2859.

11. Sawasdee P, Sabphon C, Sitthiwongwanit D, Kokpol U. Anticholinesterase activity of 7-methoxyflavones isolated from Kaempferiaparviflora. Phytother Res. 2009;23(12):1792-1794.

12. Sae-wong C, Tansakul P, Tewtrakul S. Anti-inflammatory mechanism of Kaempferiaparviflora in murine macrophage cells (RAW 264.7) and in experimental animals. J Ethnopharmacol. 2009;124(3):576-580.

13. Wattanapitayakul SK, Chularojmontri L, Herunsalee A, Charuchongkolwongse $\mathrm{S}$, Chansuvanich N. Vasorelaxation and antispasmodic effects of Kaempferiaparviflora ethanolic extract in isolated rat organ studies. Fitoterapia. 2008;79(3):214-216.

14. Tewtrakul S, Subhadhirasakul S. Anti-allergic activity of some selected plants in the Zingiberaceae family. J Ethnopharmacol. 2007;109(3):535-538.

15. Sae-wong C, Matsuda H, Tewtrakul S, et al. Suppressive effect of methoxyflavonoids isolated from Kaempferiaparviflora on inducible nitric oxide synthase (iNOS) expression in RAW 264.7 cells. J Ethnopharmacol. 2011;136(3):488-495.

16. Wattanapitayakul SK, Suwatronnakorn M, Chularojmontri L, et al. Kaempferiaparviflora ethanolic extract promoted nitric oxide production in human umbilical vein endothelial cells. $J$ Ethnopharmacol. 2007;110(3):559-562.

17. Rujjanawate C, Kanjanapothi D, Amornlerdpison D, Pojanagaroon S. Anti-gastric ulcer effect of Kaempferiaparviflora. J Ethnopharmacol. 2005;102(1):120-122.

18. Kusirisin W, Srichairatanakool S, Lerttrakarnnon P, et al. Antioxidative activity, polyphenolic content and anti-glycation effect of some Thai medicinal plants traditionally used in diabetic patients. Med Chem. 2009;5(2):139-147.

19. Horikawa T, Shimada T, Okabe Y, et al. Polymethoxyflavonoids from Kaempferiaparviflora induce adipogenesis on 3T3-L1 preadipocytes by regulating transcription factors at an early stage of differentiation. Biol Pharm Bull. 2012;35(5):686-692.

20. Okabe Y, Shimada T, Horikawa T, et al. Suppression of adipocyte hypertrophy by polymethoxyflavonoids isolated from Kaempferiaparviflora. Phytomedicine. 2014;21(6):800-806.

21. Akase T, Shimada T, Terabayashi S, Ikeya Y, Sanada H, Aburada M. Antiobesity effects of Kaempferiaparviflora in spontaneously obese type II diabetic mice. J Nat Med. 2011;65(1):73-80.

22. Shimada T, Horikawa T, Ikeya Y, et al. Preventive effect of Kaempferiaparviflora ethyl acetate extract and its major components polymethoxyflavonoid on metabolic diseases. Fitoterapia. 2011;82(8): $1272-1278$.

23. Yoshino S, Kim M, Awa R, Kuwahara H, Kano Y, Kawada T. Kaempferiaparviflora extract increases energy consumption through activation of BAT in mice. Food Sci Nutr. 2014;2(6):634-637. 
24. Matsushita M, Yoneshiro T, Aita S, et al. Kaempferiaparviflora extract increases whole-body energy expenditure in humans: roles of brown adipose tissue. J Nutr Sci Vitaminol. 2015;61(1):79-83.

25. Yoshino S, Awa R, Miyake Y, et al. Effects of single oral intake of Kaempferiaparviflora extract on energy metabolism - a randomized double-blind crossover study-. Jpn Pharmacol Ther. 2016;44(12): 1757-1762.

26. WHO. Obesity: preventing and managing the global epidemic. Report of a WHO consultation. World Health Organ Tech Rep Ser. 2000;894:i-xii,1-253.

27. Takahashi H, Mori M. Characteristics and significance of criteria for obesity disease in Japan 2011. Nihon Rinsho. 2013;71(2):257-261.

28. Ma Y, Olendzki BC, Li W, et al. Seasonal variation in food intake, physical activity, and body weight in a predominantly overweight population Eur J Clin Nutr. 2006;60(4):519-528.

29. Kajimoto O, Kajimoto Y, Yabune M, et al. Tea catechins with a galloyl moiety reduce body weight and fat. J Health Sci. 2005;51(2): 161-171.

30. Kishimoto Y, Oga H, Tagami H, Okuma K, Gordon DT. Suppressive effect of resistant maltodextrin on postprandial blood triacylglycerol elevation. Eur J Nutr. 2007;46(3):133-138.

31. Saito M, Yoneshiro T. Capsinoids and related food ingredients activating brown fat thermogenesis and reducing body fat in humans. Curr Opin Lipidol. 2013;24(1):71-77.

32. Yoneshiro T, Aita S, Matsushita M, et al. Recruited brown adipose tissue as an antiobesity agent in humans. J Clin Invest. 2013;123(8): 3404-3408.
33. Imbeault P, Lemieux S, Prudhomme D, et al. Relationship of visceral adipose tissue to metabolic risk factors for coronary heart disease: is there a contribution of subcutaneous fat cell hypertrophy? Metabolism. 1999;48(3):355-362.

34. Smith SR, Lovejoy JC, Greenway F, et al. Contributions of total body fat, abdominal subcutaneous adipose tissue compartments, and visceral adipose tissue to the metabolic complications of obesity. Metabolism. 2001;50(4):425-435.

35. Fox CS, Massaro JM, Hoffmann U, et al. Abdominal visceral and subcutaneous adipose tissue compartments: association with metabolic risk factors in the Framingham Heart Study. Circulation. 2007;116(1):39-48.

36. Adkins JC, Faulds D. Micronised fenofibrate: a review of its pharmacodynamics properties and clinical efficacy in the management of dyslipidemia. Drugs. 1997;54(4):615-633.

37. Hocking S, Samocha-Bonet D, Milner KL, Greenfield JR, Chisholm DJ. Adiposity and insulin resistance in humans: the role of the different tissue and cellular lipid depots. Endocr Rev. 2013;34(4):463-500.

38. Murphy KG, Bloom SR. Gut hormones and the regulation of energy homeostasis. Nature. 2006;444(7121):854-859.

39. Crujeiras AB, Zulet MA, Lopez-Legarrea P, et al. Association between circulating irisin levels and the promotion of weight-lowering program in obese patients. Metabolism. 2014;63(4):520-531.

40. Nagao T, Meguro S, Hase T, et al. A catechin-rich beverage improves obesity and blood glucose control in patients with type 2 diabetes. Obesity. 2009;17(2):310-317.

41. Songpol C, Pranee C, Aimmanas A, Anudep R. Chronic study of Kaempferia parviflora Wall ex. Extract. Thai J Vet Med. 2010;40(4):377-383.

\section{Publish your work in this journal}

Diabetes, Metabolic Syndrome and Obesity: Targets and Therapy is an international, peer-reviewed open-access journal committed to the rapid publication of the latest laboratory and clinical findings in the fields of diabetes, metabolic syndrome and obesity research. Original research, review, case reports, hypothesis formation, expert opinion and commentaries are all considered for publication. The manuscript management system is completely online and includes a very quick and fair peer-review system, which is all easy to use. Visit http://www.dovepress.com/testimonials.php to read real quotes from published authors. 